\title{
The concept of "palliation" in children with heterotaxy syndrome
}

Although a relatively rare subset of patients with congenital heart disease, patients with heterotaxy syndrome still present a significant management challenge. Studies over the years have demonstrated a significant morbidity and mortality associated with heterotaxy syndrome, ${ }^{1}$ and there are ongoing efforts to better define the risk factors for morbidity and mortality in this unique subset of patients.

In this issue of the Journal, Alsoufi and colleagues ${ }^{2}$ analyze 67 patients over a 10-year period with heterotaxy syndrome requiring single-ventricle palliation in their institution. The majority of their patients $(n=58,87 \%)$ required neonatal surgical palliation in the form of a modified Blalock-Taussig shunt, Norwood operation, or pulmonary artery banding. Repair of total anomalous pulmonary venous connection (TAPVC) was performed concomitantly in $30 \%$ of the patients, which was the most common concomitant surgery performed. Hospital mortality was $22 \%$ (15/67), with more than half of the nonsurvivors also having undergone concomitant TAPVC repair. In their multivariable analysis, TAPVC repair was significantly associated with higher hospital mortality, along with postoperative extracorporeal membrane oxygenation (ECMO) and need for reoperation. The association of TAPVC and heterotaxy with higher mortality is similar to other analyses of heterotaxy and single-ventricle survival. ${ }^{3-5}$ Survival to hospital discharge for their heterotaxy cohort who required postoperative ECMO was $18 \%$, significantly less than the national survival of neonatal cardiac ECMO, which is approximately $40 \%{ }^{6}$ The most significant period of mortality was in the initial first-stage palliation hospitalization. Mortality beyond the bidirectional Glenn stage was substantially less and comparable to a matched contemporary cohort of neonates with single-ventricle anomalies without heterotaxy syndrome.

Alsoufi and colleagues ${ }^{2}$ are adding to a body of data that have demonstrated that single-ventricle palliation in heterotaxy syndrome remains a significant challenge. Their sobering findings include a higher overall mortality before the

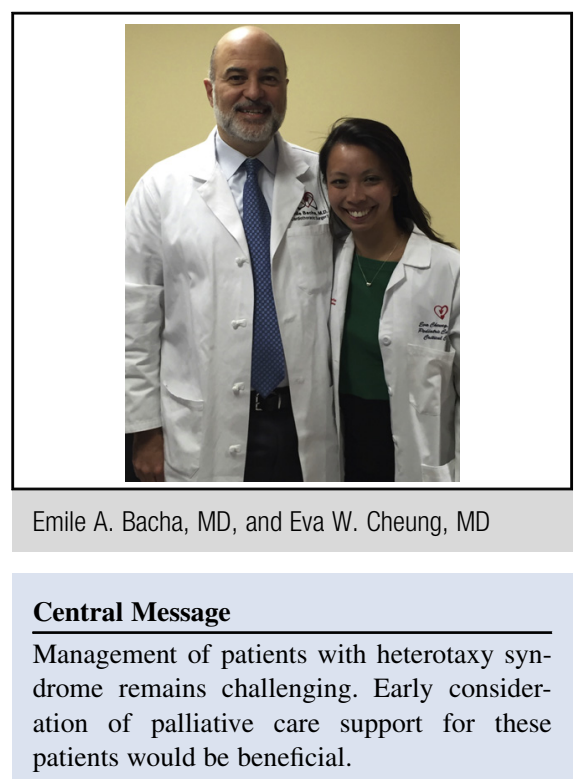

See Article page 1369.

Glenn, with a flat survival curve afterward that runs parallel to the survival curve for patients with nonheterotaxy single ventricles post-Glenn. The upfront cost is higher, so to speak, especially if total anomalous pulmonary venous return repair is required, but the survivors of this condition have the same chances of surviving long term as other patients with single ventricles. Of course, all this implies a significant use of medical resources and challenges to long-term survival with a good quality of life. ${ }^{1,7}$ What do these data mean for the practitioners at the bedside? Certainly, it means that one can more accurately counsel families of infants with heterotaxy syndrome facing single-ventricle palliation. It also means that in a setting where a neonate is doing poorly postoperatively, one might need to nuance ECMO indications for example and not necessarily always push for maximally invasive therapies. ${ }^{8}$ Families of patients with heterotaxy syndrome would greatly benefit from the early involvement of pediatric palliative care services. Palliative care services for parents with the prenatal diagnosis of hypoplastic left heart syndrome often have been framed in terms of nonintervention and end-of-life support. ${ }^{9}$ The more modern concept of pediatric palliative care has evolved beyond end-of-life or hospice care. Himelstein and colleagues ${ }^{10}$ described that "palliative care is a philosophy of care that evolved from the hospice philosophy to meet the gaps in care for seriously ill and dying patients." The aims of pediatric palliative care, whether toward the outcome ends 
in cure or death, are to improve quality of life, ameliorate pain and suffering, and provide the physical, social, psychosocial, and spiritual needs of a patient with a serious illness. ${ }^{10}$ As patients with heterotaxy syndrome facing single-ventricle palliation continue to demonstrate outcomes and morbidities more significantly than their nonheterotaxy single-ventricle counterparts, pediatric palliative care services can provide a vehicle to explore a family's goals of care for their children, to help open dialogue of the road that may lie ahead (possible multiple surgeries, ECMO, prolonged intensive care unit admissions), and explore the goals of care to provide the much needed emotional and psychologic support for this special patient population.

\section{References}

1. Jacobs JP, Pasquali SK, Morales DL, Jacobs ML, Mavroudis C, Chai PJ, et al. Heterotaxy: lessons learned about patterns of practice and outcomes from the congenital heart surgery database of the society of thoracic surgeons. World $J$ Pediatr Congenit Heart Surg. 2011;2:278-86.
2. Alsoufi B, McCracken C, Schlosser B, Sachdeva R, Well A, Kogon B. Outcomes of multistage palliation of infants with functional single ventricle and heterotaxy syndrome. J Thorac Cardiovasc Surg. 2016;151:1369-77.

3. Azakie A, Merklinger SL, Williams WG, Van Arsdell GS, Coles JG, Adatia I. Improving outcomes of the Fontan operation in children with atrial isomerism and heterotaxy syndromes. Ann Thorac Surg. 2001;72:1636-40.

4. Stamm C, Friehs I, Duebener LF, Zurakowski D, Mayer JE Jr, Jonas RA, et al. Improving results of the modified Fontan operation in patients with heterotaxy syndrome. Ann Thorac Surg. 2002;74:1967-78.

5. Gaynor JW, Collins MH, Rychik J, Gaughan JP, Spray TL. Long-term outcome of infants with single ventricle and total anomalous pulmonary venous connection. J Thorac Cardiovasc Surg. 1999;117:506-13.

6. Extracorporeal Life Support Organization. ECLS registry report. International summary. January 2016. Available at: https://www.elso.org/Registry/Statistics/ InternationalSummary.aspx. Accessed March 14, 2016.

7. Anagnostopoulos PV, Pearl JM, Octave C, Cohen M, Gruessner A, Wintering E, et al. Improved current outcomes in patients with heterotaxy syndrome. Eur J Cardiothorac Surg. 2009;35:871-7.

8. Cohen MS, Schultz AH, Tian ZY, Donaghue DD, Weinberg PM, Gaynor JW, et al. Heterotaxy syndrome with functional single ventricle: does prenatal diagnosis improve survival? Ann Thorac Surg. 2006;82:1629-36.

9. Rychik J. What does palliative care mean in prenatal diagnosis of congenital heart disease? World J Pediatr Congenit Heart Surg. 2013;4:80-4.

10. Himelstein BP, Hilden JM, Boldt AM, Weissman D. Pediatric palliative care. N Engl J Med. 2004;350:1752-62. 